\title{
ENQUADRES CLÍNICOS, ENQUADRAMENTOS estéticos. Arte e PSICANÁlise*
}

\author{
Clinical setting, aesthetic frameworks. \\ Art and psychoanalysis
}

RESUMO O artigo visa estabelecer uma articulação entre o enquadre clínico psicanalítico e a noção de enquadramento na imagem artística. Para tanto, a leitura apoia-se em questões relacionadas ao atendimento, no sentido de um setting propriamente dito, para se lançar a criações artísticas que questionam o estatuto rígido - quando é o caso - deste enquadre, passando por uma reflexão a respeito da noção de transferência, cujo fenômeno se revelaria fundamental neste contexto. As conclusões encaminham a fazer, ademais, uma aproximação direta entre a experiência estética e a experiência psicanalítica.

Palavras-chave Escuta analítica; SetTING; EXPERIÊNCIA ESTÉtICA

ABSTRACT This paper aims at establishing a link between the psychoanalytic idea of a clinical setting and the notion of framing in the artistic image. To this end, the reading is based on issues related to clinical care, in the specific sense of a setting, casting itself in artistic creations that challenge the rigid status - when it's the case - of this setting, and reflecting on the notion of transference, a basic phenomenon in this context. The conclusions refer to a direct approach between the aesthetic experience and psychoanalytic experience.

KEYWORDS: SEETTING; ESTHETIC EXPERIENCE; CLINICAL INTERVENTION

L ogo no início de “On the Couch”, intervenção para o número 113 da Revista October, lançado em 2005 e inteiramente dedicado à psicanálise, a historiadora e crítica de arte Mignon Nixon anuncia uma grave condição que vem assaltando tanto o campo psicanalítico quanto o circuito da arte contemporânea: depois de fazer suas inúmeras incursões, mais ou menos abrangentes no cenário cultural, a psicanálise agora se vê, em paralelo à reflexão estética, segundo ela, diante da obrigação de fazer um novo retorno - novo porque vem depois de Lacan, evidentemente - às origens de seu "dispositivo". ${ }^{1}$ No que concerne à produção artística, por outro lado, o estado de coisas revela-se,

* O ensaio é derivado de tese de doutoramento em Psicologia, defendida em 2010 no Instituto de Psicologia da USP-SP.

Dispositivo não é, a rigor, um conceito psicanalítico. Por ele podemos entender aqui, grosso modo, a soma de atributos teórico-técnicos exigidos pelo atendimento clínico em psicanálise, tendo em vista que, de antemão, tais preceitos orbitam ao redor da transferência, sem a qual não existe técnica que se sustente. Sublinho o problema, pois não se deve confundi-lo com a categoria foucaultiana de dispositivo, que não possui a mesma significação.
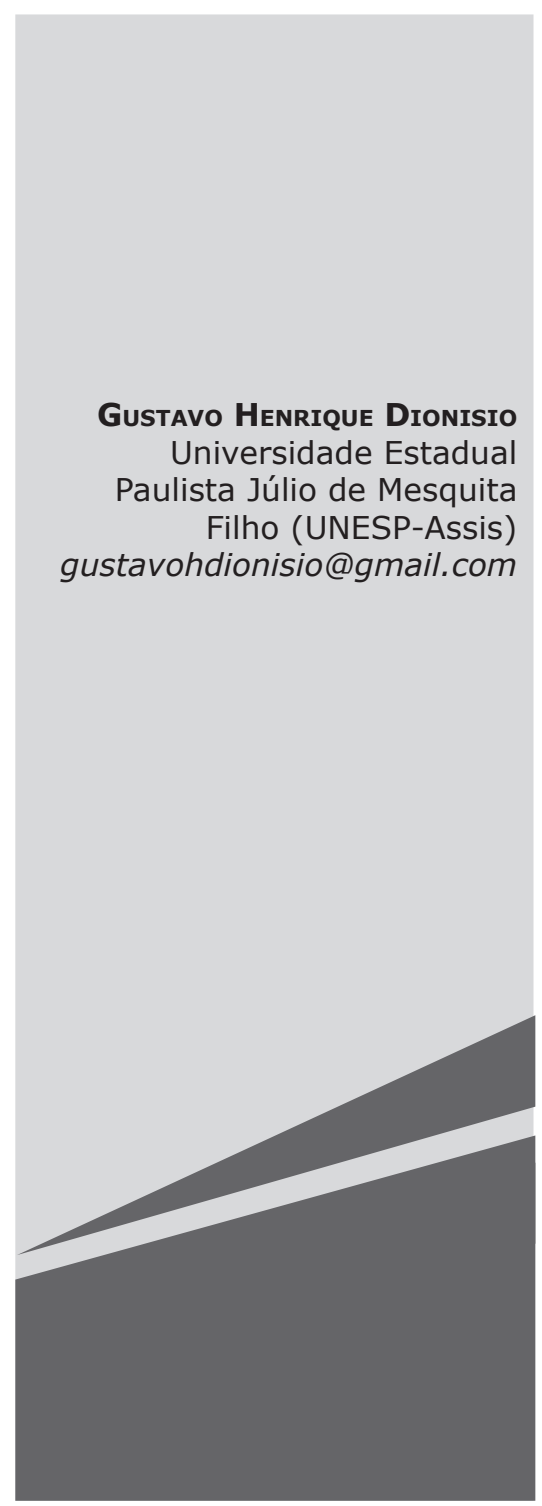
segundo ela, surpreendentemente semelhante. Ambas teriam chegado ao ponto da "máxima resistência", como indica a historiadora, que seria o "da análise do enquadre". Reorganizar balizas e aparar arestas são, portanto, as grandes metas para a psicanálise e para a arte dos anos 2000.

Mas, uma vez dadas as transformações que ambas já viveram ao longo da toda a história, para onde mais se dirigir? Nas palavras de Nixon,

A sobrevivência do artista como figura pivô no pós-modernismo, para além da suposta morte do autor uma tendência central em muito da arte conceitual - evidencia por ela mesma o papel que a transferência ganha ao estabelecer, e sustentar, uma dinâmica de transferência em arte. Um artista não identificado descrevendo uma obra não identificada para outro artista não identificado produz transferência à audiência [...] A presença de um ouvinte na cena, mesmo (ou sobretudo) sendo ele silencioso e invisível, estimula a dinâmica. O que é de ainda maior interesse às histórias da arte conceitual e da crítica institucional, entretanto, é a transferência para o enquadre. (NIXON, 2005, p. 45 , tradução livre e grifos meus).

Fato hoje conhecido, foi com o surgimento da arte conceitual que certos elementos, até então considerados adjacentes à obra, passaram a ser obra, sendo então incorporados em definitivo ao objeto de arte e, para observar o fenômeno, basta ir a qualquer mostra mais ou menos recente. Até os horários de abertura e fechamento da exposição deixariam de ser coadjuvantes, por exemplo, assim como o tempo de duração da exibição; hoje, a função assumida pelos textos críticos e catálogos também compõe a obra etc. Com isso, não se poderia considerar que, em paralelo ao que ocorre na prática analítica, o "enquadre" da arte se situaria na relação de transferência, e então não se limitaria aos preceitos técnico-práticos definidos de antemão? É o que parece indicar o texto de Nixon para October.

Mas talvez a pergunta seja um tanto autoexplicativa. Nestas condições o texto crítico, criado ou não sob encomenda pela curadoria de uma exposição, adentra os perímetros do objeto e exige ocupar um lugar de verdadeira coautoria, como assim sugere Sonia Salzstein (2008). Em outras palavras, isto significa reconhecer que o paradigma da chamada psicanálise "aplicada" ainda continuaria movimentando fantasmas e atingindo o cenário da reflexão estética mais recente. Prosseguindo com a opinião de Nixon,

É dado na crítica contemporânea que teoria e prática da psicanálise são separáveis, que a teoria psicanalítica alcançou uma autonomia em relação a seu quadro geral. Mas esta divisão (em termos psicanalíticos, esta cisão), tem dado margem a uma psicanálise acadêmica que é com frequência abandonada, com certa justiça, porque institucionalizada, dócil, dogmática - uma forma de crítica cultural em que o crítico de fato "encara a si mesmo como um sujeito que sabe o que está acontecendo". (2005, p. 76, tradução livre minha).

Com isso, ou seja, ao amparar-se na facilidade da aplicação, o horizonte do enquadre flerta com o perigo de cair nas malhas da violência interpretativa. Diante da obra ou do paciente, psicanalistas e críticos precisam vigiar-se o tempo todo, neste sentido, para não se acomodar. Já os artistas, por sua vez, conseguiriam problematizá-lo sem tanta dificuldade. E é justamente nesta medida que a problemática pode ser ampliada teoricamente.

Uma reconstrução histórico-fotográfica de consultórios, trazida à tona pela própria Mignon Nixon, não poderia ter um melhor emprego. Tais registros, que nascem em maio 
de 1938, quando Freud ainda atendia na Bergasse 19, partiram da iniciativa de Edmund Engelman, fotógrafo trazido ao seu consultório pela mão de August Aichorn. Não deve causar espanto que, no conjunto de retratos analisados por Nixon, se destaque a importância que o divã viria a ganhar, em termos formais, nas imagens disponíveis, a começar pelas peças que pertencem ao Museu Freud de Viena. Mas o destaque torna-se ainda maior quando lançamos o olhar ao Museu Freud londrino, uma vez que nele se conserva o móvel original que pertenceu ao criador da psicanálise.

Mas, afinal, por que levantar a questão sobre a presença do divã se hoje em dia ele já é tão questionado - e isso nos próprios termos de um setting, por assim dizer - pela influência cada vez maior das psicoterapias breves? Para os propósitos desta reflexão, a pergunta, que aparenta ser um tanto despretensiosa, conduz o interesse de volta ao epicentro da questão do enquadre na psicanálise e na arte, e isto porque acessar a presença do divã significa reativar a problemática do olhar. Deste modo, pretendo apresentar alguns exemplos nos quais os artistas fazem obra desta discussão sobre o enquadre. Com isto e depois de algumas torções -, a reflexão permitirá acedermos ao ponto de estabelecer em que medida a escuta clínica pode aproximar-se de uma experiência de recepção estética.

\section{PONTUAÇÕES BREVÍSSIMAS SOBRE O DIVÃ}

A historieta que ilustra uma das pedras angulares da análise já deve ter entrado nos ouvidos de boa parte daqueles que se dizem psicanalistas: Freud, além de não desejar que suas expressões faciais interferissem na fala do paciente, procurava evitar a "vazão" de seus pensamentos inconscientes ao longo da sessão; tampouco gostava de ser olhado durante um dia inteiro, conforme testemunhou em 1913 (FREUD, 1996). Desse modo, o "quadro analítico é concebido e anunciado a princípio por Freud como uma comodidade", assinala a esse respeito Serge Viderman, "ou como o vestígio do método do qual acabava de libertar-se" (1990, p. 36-37), a saber, a hipnose. Mas não só: em uma perspectiva mais ampliada, a renúncia visual no contato entre analista e analisando teria a função de "efetuar um deslocamento do desejo escópico do rosto do analista para o meio ambiente da análise" (NIXON, 2005, p. 49), o que faz com que neste pacto (implícito) todo mundo saia ganhando.

No início, não obstante, tais preceitos técnicos não deviam ser tomados como pontos fixos ou estratégias dogmáticas, pois funcionaram apenas como sugestões. Mas, se aquilo, do contrário, vem a acontecer, assistiremos a outro processo também elucidado pelo próprio circuito psicanalítico: repressão, aquilo que de fato viria a acontecer em função do excessivo rigor aplicado neste contexto por uma atitude "organizadora" como a de Wilhelm Reich. Para este, na compreensão de Serge Viderman, "se é possível haver muitas maneiras de fazer análise aceitável”, haveria, entretanto, "apenas uma para fazê-la a meIhor possível” (VIDERMAN, 1990, p. 42).

Por outro lado, como se sabe, é impossível tornar-se analista apenas ao interpretar a letra freudiana como um livro de receitas a ser seguido passo a passo. Pelo sim e pelo não, o divã - "essa montanha russa!", como diria um paciente, iria se tornar, com efeito, "um ícone da cultura moderna” (NIXON, 2005, p. 40). São escassas, no entanto, as linhas em que Freud dedica-se a ele, e de igual forma, a literatura psicanalítica quase nunca discute o assunto, talvez por tratar-se de um procedimento técnico relativamente pouco controverso. Ora, não é incomum constatar que muitos analistas avaliem que o divã seja uma ferramenta privilegiada no processo terapêutico.

O divã vem caminhando, portanto, no fio da navalha. A liberdade que ele proporciona pode ser diretamente proporcional à escravidão que também viria a enlaçar quando o uso torna-se enrijecido. Dentre os principais autores que investigam o assunto, Serge Viderman destaca que

Se a regra fundamental permanece declaradamente a das associações livres do paciente, as regras 
que se impõem ao analista não são nem menos essenciais nem menos constrangedoras para completar e definir a estrutura específica da situação analítica. Tratando-se das posições respectivas no espaço analítico, o divã e a poltrona são estritamente complementares [...] é um fato que tais razões, casuais ou por conveniência, tornaram-se necessidades tanto mais imperativas quanto a força e a evidência dos fenômenos transferenciais se achassem ali rigorosamente interligadas. (1990, p. 40).

Não estamos noutro lugar, senão naquele que entende o processo em sua medida transferencial. Esta lógica implicaria que, se a cena psicanalítica for referida como enquadre, sua quebra será entendida fatalmente como resistência. O enquadre, apesar da dissimetria essencial que representa e que é própria da relação analítica, é o procedimento que dá continência ao enigma de se fazer... psicanálise. Em meio à dissolução subjetiva que ocorre no caminhar das sessões - seu aspecto mais "regrediente", conforme atesta a pesquisa conduzida por Cesar e Sára Botella (2007) -, deve permanecer a constância do enquadre. Com isso, o enquadre tem a responsabilidade de, em boa parte, sustentar o liame analítico, de modo que é também a sua existência que permite a saída do processo. Tal qual a artista Mary Kelly conseguiria demonstrar - sem ser analista - em obras como Post-partum document e Interim, toda resistência implica transferência, sendo que esta dupla é parte constituinte da ideia mesma de enquadramento.

\section{ARTE de CONSULTóRIO}

A fotógrafa americana Shellburne Thurber iniciou um grande projeto que visava documentar consultórios de psicanalistas durante o período que viveu em Buenos Aires. De volta a Boston, continuou a retratá-los, no entanto concentrando-se no divã e em sua disposição no interior da sala: o tamanho e o lugar do analista em relação ao móvel, bem como a posição de mais ou menos destaque que ganhava dentro do cenário. Se a associação livre está para o divã assim como a poltrona está para a atenção flutuante, a disposição poderia indicar, assim, uma perfeita simetria: "para a palavra de um e para que essa palavra se fizesse entender melhor, o silêncio do outro; escuta e acolhida, a atenção é sempre estendida para o discurso do outro" (VIDERMAN, 1990, p. 42).

Por outro lado, as imagens de Thurber podem sugerir a hipótese de que está em ação, no espaço físico dos consultórios, um tipo muito especial de sobredeterminação psíquica: o olhar da fotógrafa descobre que a maioria dos divãs retratados em sua pesquisa aparentava-se muito ao estilo da peça utilizada originalmente por Freud, sobretudo porque os "símbolos poéticos" (NIXON, 2005, p. 52) da cultura mais contemporânea invadiam a cena com raríssima frequência. $E$ a despeito do arranjo mais geral de sala, os demais objetos dão brecha para que o analisando consiga experimentar algo do "sabor pessoal" que cada analista possui: quais são os livros, os quadros, as imagens dispostas, quais as coleções oferecidas à vista e daí por diante.

Isto posto, não é preciso ir mais longe: como se pode inferir por meio de uma análise "institucional" do dispositivo psicanalítico, a onipresença do divã forneceria identidade, ao mesmo passo em que garantiria legitimidade a quem pratica o atendimento, principalmente se pensarmos na verdadeira crise que o consultório psicanalítico vem passando ao longo dos últimos anos. Assim, não é à toa que divã e enquadre surjam potencialmente no rol das discussões institucionais.

Ao contrário dos artistas, grande parte dos psicanalistas não toma as características de sua sala de atendimento como fazendo parte do setting. É claro que essa maioria tem consciência de sua disposição, ou mesmo das associações que podem gerar, mas, ainda assim, poucos meditam sobre suas condições concretas de uso ou as variâncias a serem 
consideradas. Isso, de maneira geral, também acontece em função de uma prescrição técnica: o consultório não poderia representar uma grande fonte de sedução, e, consequentemente, de "escopofilia"? Quando ocorre, e se os pacientes se referem, por exemplo, ao mobiliário, ao maior ou menor conforto do divã e da sala, tudo isso encaminha o profissional a trabalhar no registro (ético) da transferência e, neste contexto, a quebra do enquadre será inevitavelmente interpretada, mais uma vez, como resistência. Pois bem, mas ainda caberia dizê-lo nestes termos?

Na leitura de Nixon - isto é, de uma historiadora da arte -, tais constatações condizem com duas grandes modalidades de interesse pela psicanálise que surgiram na arte contemporânea: a primeira, mais inclinada à arte conceitual, manifesta uma maior preocupação pela "lógica freudiana de colecionar e é materializada particularmente no suporte de objeto-base ou fotográfico". No segundo caso, vê-se uma busca para "explorar, por meio do vídeo, a 'dinâmica da transferência' em Psicanálise” (2005, p. 59). Vejamos mais de perto.

Com referência ao hábito colecionador de Freud, tem-se o trabalho de Susan Hiller que, em meados dos anos 1990, apresentou uma obra composta por cinquenta caixas de madeira numeradas, cujo molde segue a forma dos recipientes que guardam amostras arqueológicas; em seu interior dispõe-se uma seleção variada de objetos, e ali cada uma das caixas é arranjada, intitulada e acompanhada por um pequeno texto ou imagem adjacente. Para Nixon, influenciado, tanto pelo "gabinete de curiosidades" quanto pelo FluxBox, After the Freud Museum (esse é o título do trabalho) "faz da heterogeneidade da coleção de Freud seu princípio organizador" (2005, p. 59, grifos meus). Não haveria aí uma espécie de "mal de arquivo" implícito - para retomar a expressão consagrada por Derrida -, que se expressa pela via dos procedimentos de acumulação? De tudo que Freud colecionou, é certo que sua arqueologia da psique iria se transformar no que há de mais significativo, e o extenso elenco de atos falhos, sintomas e piadas que acumulou é, neste sentido, prova inequívoca.

No mesmo ano, outra artista - Cornelia Parker, nomeadamente - retirava plumas de travesseiros nos quais "analisandos um dia se deitaram" e, a partir desse "traço de talking cure, produziu outro, um fotograma". A artista colecionou também as cinzas de cigarro que grudavam aos panos de limpeza do Museu Freud, assim como "coletava exalações de Freud como material para desenho" (NIXON, 2005, p. 60). Seu interesse maior era retratar o caráter histórico da "pessoa Freud", incorporando à sua obra os vestígios corporais acessíveis na sala, ação análoga à qual Freud desejara empregar em sua análise do mito de Leonardo, ainda que utilizando métodos claramente distintos.

Todos estes trabalhos (Hiller, Parker e Thurber) dialogam com a vontade colecionadora de Freud sem revelar, todavia, a intenção de reunir um arquivo geral. Pelo contrário, limitam-se a apresentar pequenos fragmentos a seu respeito, indícios, a exemplo do que fez o próprio criador da psicanálise. "O modelo de coleção em Freud é expansivo, porém seletivo", prossegue Nixon no ponto alto de seu ensaio, e sempre "aspira iniciar novas coleções - sonhos, parapraxias e piadas", combinando-as "à coleção de objetos da antiguidade que representavam, para ele, a própria civilização" (2005, p. 61).

Fato público, o Museu Freud de Londres propõe-se a realizar exposições de artistas recentes envolvidos com a psicanálise. Neste ínterim, Sarah Lucas apresentou, em 2000, a performance Beyond the Pleasure Principle (Além do princípio do prazer). A partir de uma "série selvagem e bem humorada de intervenções", ocupou os cômodos do prédio "com instalações de mobiliário invertido", roupas íntimas e, em um lugar bastante destacado - leia-se, logo acima do divã - "uma fotografia ampliada do torso sem cabeça da artista, e que mostra um mamilo saindo maliciosamente de um buraco pela sua camiseta" (NIXON, 2005, p. 62). Nas entrelinhas, como se pode notar, representa-se a disputa magna 
entre Melanie Klein e Anna Freud no contexto do poder institucional psicanalítico. Para a historiadora americana, no entanto, o que mais se destaca aqui é a transgressão de setting que a instalação de Lucas vem insinuar: "uma fragmentação espetacular do enquadre que o museu" acomodaria, ironicamente, "com prazer" (2005, p. 63). Ora, a dinâmica transferencial destas imagens ganha ainda maior sentido quando se percebe que

Ao demonstrar seu desafio ao mestre com respeito ao setting - isto é, acessando, no contexto de seu milieu, uma transferência negativa em relação à psicanálise - Lucas também reivindica a Psicanálise para si mesma. Emprestando o título de uma obra de Freud, na qual o próprio mestre se encontra cercado por suas teorias, Beyond the Pleasure Principle usa a Psicanálise como um objeto que, tal como pensa Juliet Mitchell, sobrevive através do todos nossos esforços para destruí-lo. (2005, p. 64).

É nesta medida que o apontamento de $\mathrm{Ni}$ xon ganha força no interior da discussão: com efeito, Além do princípio do prazer é o lugar para o qual convergiu uma parcela significativa da reflexão estética contemporânea. Críticos como Hal Foster, Rosalind Krauss e Benjamin Buchloch podem ser destacados aqui, assim como o filósofo Georges Didi-Huberman. No que tange à produção artística, por outro lado, o mérito de Sarah Lucas é o de ter figurabilizado esta ferida na carne mesma da arte. Se a leitura psicanalítica ainda faz algum sentido para a experiência estética é porque seu modo de ler sobrevive na resistência contra as estratégias destrutivas que a ela se dirigem neste cenário. A teoria torna-se aqui objeto, como assim refere Juliet Mitchell em seu ensaio para o mesmo número de October (2005).

The Orange and Blue Feelings, que $\mathrm{o}$ artista Glenn Ligon realizou em 2003, também expressa uma vontade de adentrar nesse pano- rama. Trata-se de um vídeo, editado a partir de três sessões nas quais se encontram dispostos o artista e sua analista. Ambos aparecem em movimento, embora o rosto da profissional e a imagem de Ligon, sempre fora de quadro, jamais sejam vistos. Existem alguns objetos distribuídos pela sala, mas eles tampouco são explorados. A câmera, em certo momento, concentra-se na janela que dá para a rua, de modo que o vídeo passa a apresentar a inquietude e a ansiedade de Ligon "concernentes a um trabalho recente". A obra retrataria, afinal, uma psicanálise in media res: "A figura da analista, com sua voz rouca, com sua esquiva coquete e vestido flamboyant, é filmada com total imparcialidade" (NIXON, 2005, p. 64). Com o vídeo, ademais, Ligon mostra sua agonia diante da possibilidade de que a terapia venha a "viciar sua arte" (NIXON, 2005, p. 66), preferindo então destinar, adiante, arte e análise a lugares rigorosamente separados.

Isso não seria uma espécie de transferência lateral ou, uma vez mais, uma nova forma de resistência? Nixon atém-se à primeira hipótese: é fato que alguns pacientes cometem a passagem-ao-ato de serem, por impulso, “infiéis” à situação analítica, deixando de trazer a exploração de seus desejos para a sessão. Ligon, no entanto, tem a consciência desta contenção e sabe o quão prejudicial ela pode se tornar para o liame transferencial. "Sua solução", por outro lado, "é fazer de sua terapia objeto de sua arte ao transformar o consultório em set para dentro dele filmar. Este gesto, todavia, vai além da infidelidade com respeito à situação analítica e a dissolve" (2005, p. 66, grifos meus). Não se poderia dizer, na esteira desta obra, que criar em transferência significaria precisamente isso? Descolar, libertar, sair... em suma, conduzir a análise, não ao seu final, mas a um final possível.

\section{RUPTURAS DE QUADRO}

A meu ver, no entanto, o grande acting-out do filme de Ligon é a fragmentação que ele imprime nos limites do enquadre. No dispositivo oferecido pelo artista, o analista já não é mais o "diretor do método", conforme 
designava Jean Laplanche. "Paradoxalmente, o enquadre é a única coisa que o analisando pode recusar", escreve a esse respeito Radmila Zygouris, "já que é da ordem do manifesto e exige um acordo prévio entre as duas partes, mesmo que pareça ser imposto pelo analista como se não houvesse escolha" (1999, p. 18).

Dirigir o método não significa dirigir a análise, que é um processo muito mais amplo; ainda que em certos momentos o analista venha a ser "a estrela do show", isso não significa que o analisando deva abandonar seu lugar de personagem principal. Mas, ao meditarmos sobre a situação proposta pelo artista, ainda poderíamos dizer que uma análise estaria ocorrendo? No "vídeo de Ligon", afirma Nixon, "a análise se dissolve", ainda que a "traição" do analisando possa oferecer possibilidades futuras de "realocação" do enquadre, a partir da ideia de "transferência da transferência” inspirada em Laplanche. Em minha opinião - e acredito não estar sozinho -, o encadeamento da transferência é diretamente proporcional ao estabelecimento do enquadre. $E$, nesta conjuntura, eles podem ampliar, ou mesmo esgotar, a intervenção, seja no espaço analítico seja no exercício de reflexão sobre arte.

Em uma escrita que se aparenta à vinheta clínica, é de maneira surpreendente que Nixon retrata a conversa entre o artista e sua terapeuta:

“Um menino fez isso?", a terapeuta pergunta. "Acredito que era um garoto", Ligon responde de modo incerto, mostrando-se curioso diante do que diz a terapeuta, "a não ser que eu esteja me projetando para trás". Em seguida, a terapeuta se interessa pelo fato de que o artista copia. Mesmo quando criança, declara, ele "nunca desenhava por imaginação", preferindo copiar de fontes materiais. "Talvez seja tempo", ela insiste, "talvez tenha se passado um longo tempo". "Jogar seus estênceis no fogo, por assim dizer?", Ligon demanda. "Mmm, não sei". "Eu tenho uma grande ansiedade com relação a falar do trabalho artístico em terapia". Ele relata sobre fazer arte na escola quando ainda era criança, sobre quando foi ridicularizado por uma professora ao ter pintado o mar com azul e laranja num papel-machê. "Você pensava que a aula de arte deveria ser aquela em que tudo seria bom, onde não existiriam regras", ela devolve. "Todo mundo tem suas coisas", relembra. "No fim, pintei de preto o barco." "Você não gosta das minhas cores. Vá se ferrar", a terapeuta brinca. "Estava pensando nas pessoas ouvindo esta conversa na galeria", ele comenta. “É embaraçoso." (2005, p. 67).

A vídeo-análise foi exposta junto com um retrato original de Malcolm X feito por um dos alunos de Ligon. O desenho - que estava a princípio no lixo - foi recuperado pelo artista entre a primeira e a segunda sessões de gravação, para então ser exposto. Ligon não lembrava, contudo, se havia relatado o fato à analista, mas aquilo que não queria ou não podia dizer em sessão acabará retornando, sob a forma de um ato, no final da história; a revelação desta lateralidade é concomitante ao término do vídeo e ao rompimento da análise, da qual o artista viria a se desligar pouco tempo depois da primeira exibição de The Orange and Blue Feelings.

Quanto a isso, avento a hipótese de que teria ocorrido uma "transferência da transferência", como diria Laplanche; a dissolução da análise pode significar o deslocamento da transferência para outros lugares e outras possibilidades - o que não traz muita novidade em termos psicanalíticos; entretanto, a tonalidade confessional que $\mathrm{Li}$ gon imprimiu em seu trabalho foi vista com surpresa e desapontamento até pela crítica. Nesta perspectiva, seria o caso de associar esse autocentramento à "estética do narci- 
sismo", proposta de Rosalind Krauss que vai em direção à vídeo-arte? Para a autora, haveria, neste suporte, uma ação reflexiva - no sentido do que acontece diante de um espeIho -, em cujo seio reside a alienação do eu pelo eu. Assim, a ausência de texto garantiria o "fascínio narcisista" da arte do vídeo.

Não obstante, as coisas não parecem ser tão diretas; em toda análise a existência do outro está colocada de antemão, e o simples fato de que ele exista faz com que o sujeito se remeta ao outro de si mesmo, princípio inexorável de alteridade que o dispositivo psicanalítico veio demonstrar definitivamente. Em análise, as intervenções dirigem-se ao outro e ao Outro. Talvez se pudesse mesmo dizer que esta é a função princeps da contratransferência, fenômeno que inevitavelmente vem antes, como sugeriria, não sem astúcia, Radmila Zygouris. Ora, nada melhor do que a dissimetria do enquadre para dar provas desta diferença. "No vídeo de Ligon", por exemplo, "a dissimetria é o princípio organizador. Terapeuta e paciente estão relegados a planos diferentes. Um é visível, o outro não. Um é homem, o outro é mulher. Um é branco e o outro, como se sabe, é negro" (NIXON, 2005, p. 68). Os personagens não escapam de deparar-se com os limites de um desencontro.

An inadequate history of conceptual art, de Silvia Kolbowski, seria aqui o último dos exemplos que visam esta problematização do enquadre. Seu processo de criação consiste em um convite enviado a sessenta artistas para depor, de memória, a respeito de alguma experiência de criação da qual tivessem participado entre os anos de 1965 e 1975. Surpreendentemente, um número relevante de depoimentos viria a ganhar um tácito matiz psicanalítico: alguns participantes esqueciam detalhes, outros declaravam, ao pé da letra, resistir às lembranças, outros repetiam episódios etc.

História inadequada... não poderia ser outro nome a ser dado à própria história da psicanálise? Ora, se "o sujeito da psicanálise é construído por resistência e repressão, tan- to no esquecimento quanto na lembrança", talvez pudéssemos dizê-lo. A instalação de Kolbowski, além de ampliar as fronteiras da história da arte conceitual, acaba provocando um debate sobre a memória. Com seu procedimento, dentro do qual a fala e a gesticulação são amplamente retratadas, evoca-se, mais do que um simples jogo de cena, o "discurso híbrido que constitui uma das principais descobertas clínicas de Freud" (Nixon, 2205b, p. 73): que as palavras e os gestos de um analisando podem não necessariamente carregar a mesmíssima mensagem.

No filme, a voz de Kolbowski nunca aparece. "Seu papel de estimular e coletar histórias orais é marcada somente pela textura de um silêncio e de uma invisível presença", o que a aproximaria, de modo definitivo, da posição em que se mantém o analista. Pensemos no dispositivo da artista, praticamente homólogo à ideia de setting; o convidado era instruído a não pesquisar antecipadamente a obra a ser descrita - fórmula que segue a máxima da associação livre -, bem como a "não revelar sua própria identidade e não revelar a autoria do trabalho descrito". Tais regras serão, no entanto, quebradas pelos depoentes em alguns momentos, tal como ocorre dentro de uma sessão analítica. Deve-se mencionar, neste sentido, que este traço é parte constituinte de seu processo de criação.

Com seu procedimento, Kolbowski teria então questionado "psicanaliticamente a história da arte conceitual, ao demonstrar que aqueles que a testemunharam, e mesmo aqueles que a produziram, não conseguem se lembrar dela de maneira exata" (NIXON, 2005, p. 74-75, grifos meus). Mas isto não é tudo. Indiretamente, ela propõe rupturas que devem ser levadas a sério pelo dispositivo clínico, afinal, que história conhecemos da psicanálise? Que história pode-se fazer da psicanálise tendo em vista toda a problemática que ela mesma engendrou? E o que dizer desta história após a inauguração de categorias como recalcamento, repetição, lembranças encobridoras, que tocam fundo neste problema do arquivo? 


\section{DOUTOR, NOSSO TEMPO ACABOU?}

Os problemas apresentados pelas fotografias de consultório e pelos vídeos de Ligon e Kolbowski provocam - aspecto que a intervenção de Mignon Nixon não consegue alcançar - pensar a respeito de uma questão decisiva para o campo analítico, questão à qual o enquadre sempre se exige retornar. O pressuposto de uma escuta que seja rigorosamente sensível é a origem mesma das pesquisas freudianas, assim como se pode dizer que a teoria psicanalítica só teria começado a partir do momento em que a senhorita Emmy Von N pede para ser ouvida e nada mais. Se a talking cure não é uma exclusividade da psicanálise, nem por isso seu palco de intervenção deixa de ser privilegiado no que tange à sua prática. Sem dúvida, equivalente a ela, a experiência com a arte é capaz de edificar, de modo singular ou mesmo antecipatório, conhecimentos ilimitados sobre o campo psíquico. Quanto a isso, Freud nunca deixou de reconhecer que a experiência com a arte lhe permitiria "baixar as armas".

Em outras palavras, é possível estabelecer que transferência e enquadre, escuta e interpretação, mas também experiência estética e experiência psíquica, andam de mãos dadas. Em sessão, a interpretação é representada por uma fala mais ou menos adequada, embora o mais importante é que ela seja "encontrada", ou melhor, "criada", na relação analítica. Eis o que articula interpretação e transferência: a interpretação é sempre operacional, processual e coparticipativa; quando o psicanalista a emite, tem em mente que partirá "por obrigação" das associações que o analisando vai fazendo em seu processo particular. Neste sentido, Viderman estabelece as diretrizes de maneira lapidar:

Do autoritarismo dos Estudos... à atitude marcada por um apagamento empírico mas que não percebeu, ainda, sua justificação teórica [...] anunciavam-se as linhas que a teoria da transferência vai traçar, cada vez mais decisivamente, para cer- car um meio específico que não fará apenas o papel de um revelador deixando ver o que fora antes ali impressionado - mas, sim, um papel ativamente criador que não é nem o passado passivo nem o presente contingente: uma dialética subvertendo as duas dimensões temporais na análise. (1990, p. 37, grifos meus).

E é assim que a psicanálise, como práxis teórico-clínica, nasceria no après-coup do dispositivo inventado por Freud e só depois do paciente - algo que porventura se poderia sumarizar com a noção de Nachträglichkeit (posterioridade), proposta pelo criador da psicanálise. "Trata-se, no processo analítico", declara a esse respeito Daniel Delouya, "assim como nos privilegiados insights gerados na vida cotidiana, de um vivido, configurado como tal quando um elemento recalcado adentra a consciência, ou seja, se torna experiência, vivência afetiva". Como é sabido, o encadeamento do processo leva o sujeito a deparar-se com um problema central: "o contato e qualidade imediata e sensível da coisa do inconsciente" (2003, p. 18). Desse modo, a essência mesma do trabalho "já afasta a psicanálise de todo e qualquer pressuposto do método científico" e de seus recursos quantificáveis, fazendo com que se aproxime, cada vez mais, da estética. "O método analítico", lê-se em Epistemopatia, "atravessa, visa atingir e resgatar o contato com o objeto" (DELOUYA, 2003, p. 34-38, grifos meus).

Segundo Radmila Zygouris, todo o dispositivo da análise comporta duas características de cunho pulsional que muito nos interessam pelo momento: "o aspecto estático que imobiliza e usa as pulsões na manutenção da estase" e "o aspecto dinâmico que leva à mudança" (1999, p. 17). Ainda que o analista seja responsável pelo direcionamento da regra fundamental, isso não significa que o enquadre tem o direito de fechar-se ad absurdum em uma ritualização de si mesmo. Para existir, o enquadre deve abrir-se a dimensões mais ampliadas do processo. Antes da relação 
de transferência, que seria, a meu ver, uma espécie de metalinguagem do si mesmo, reside uma precondição do contato, pulsão básica da existência a ser definida como um vínculo, inédito, por sinal, e que nunca se repete. Em paralelo, seria exatamente o que acontece na presença da obra de arte: a atividade de recepção estética exige um vínculo que não é de outra ordem senão vivencial.

Para concluir, pode-se dizer que a análise seria o limiar ótimo para se trabalhar com o "Isto quer dizer aquilo". Ainda de acordo com Zygouris: o "isto" - que aqui pode ser assumido pela composição, pela obra e pelo vínculo - demanda inevitavelmente um dizer sobre si, sendo que "aquilo" toma o lugar da interpretação ou de um saber, enfim, construído. "Aquilo" é, portanto, nada mais que um meio aproximativo para se representar o que é "isto". Em sessão, o isso (id) pode abrir-se na presença de alguém que ganha importância transferencial, o que proporciona um largo espaço para a criação, e assim o prazer pulsional do isso pode expressar-se justamente aí (2002, p. 44). Deste modo, portanto, torna-se possível escapar da repetição compulsiva que acomete o apareIho. É que neste grande intervalo, que vai do paciente ao analista, da obra ao analista, e do analista ao paciente e à obra, reside a sensibilidade de um olhar que é também escuta.

\section{REFERÊNCIAS}

BOTELLA, C.; BOTELLA, S. La figurabilité psychique. Paris: In Press, 2007.

DELOUYA, D. Epistemopatia: o conhecimento na clínica psicanalítica. São Paulo: Casa do Psicólogo, 2003.

DIONISIO, G. H. Pede-se abrir os olhos: psicanálise e reflexão estética hoje. São Paulo: Annablume-Fapesp, 2012.

FREUD, S. Sobre um caso de paranoia descrito autobiograficamente, trabajos sobre técnica psicoanalítica y otras obras. In: Obras completas. Buenos Aires: Amorrortu, 1996. v. XII. (Original de 1913).

KELLY, M. Post-partum document. 1973. (Obra de arte) (http://www.marykellyartist.com/post partum_document.html)

. Interim. 1984-1989. (Obra de arte). http://www.marykellyartist.com/interim.html

$\overline{\text { KOLBOWSKI}}$, S. An inadequate history of conceptual art. 1998-1999. (Obra de arte). http:// www.secession.at/art/2004 kolbowski e.html

LIGON, G. The orange and blue feelings. 2003. (Obra de arte).

http://www.regenprojects.com/artists/glenn-ligon/\#1

NIXON, M. On the couch. October, Cambridge, MA, n. 113, Summer 2005.

MITCHELL, J. Theory as an object. October, Cambridge, MA, n. 113, Summer 2005.

SALZSTEIN, S. Transformações na esfera da crítica. In: FERREIRA, G. (Org.). Crítica de arte no Brasil: temáticas contemporâneas. Rio de Janeiro: Funarte, 2008.

VIDERMAN, S. A construção do espaço analítico. São Paulo: Escuta, 1990.

ZYGOURIS, R. Pulsões de vida. São Paulo: Escuta, 1999.

. $O$ vínculo inédito. São Paulo: Escuta, 2002.

DADOS AUTORAIS:

Gustavo HenRique Dionisio

Universidade Estadual Paulista Júlio de Mesquita Filho (UNESP-Assis). Graduado em Psicologia pela UNESP-Assis (2002), mestrado (2004) e doutorado (2010) em Psicologia Social da Arte pela Universidade de São Paulo (USP), com estágios na Pitié-Salpetriêre e ÉHESS (Paris).

É professor de Graduação e Pós-Graduação no departamento de Psicologia Clínica da Universidade Estadual Paulista Júlio de Mesquita Filho (UNESP-Assis).

Recebido: 13/02/2014

Aprovado: 02/04/2014 